\title{
ESTABLISHMENT AND VERIFICATION OF A NEW PREDICTION MODEL FOR DRY RUBBER YIELD
}

\author{
HUANG, H. ${ }^{2,3}-$ YANG, Z. $.^{1 *}-$ WANG, C. ${ }^{3}-$ ZhANG, J. ${ }^{2,3}-$ LI, Y. ${ }^{1}-$ HU, D. ${ }^{2}-$ LIU, W. ${ }^{1}$ \\ ${ }^{I}$ Collaborative Innovation Center on Forecast and Evaluation of Meteorological Disasters, \\ Nanjing University of Information Science \& Technology, Nanjing 210044, Jiangsu Province, \\ P. R. China \\ ${ }^{2}$ Hainan Climate Center, Haikou 570203, Hainan Province, P. R. China \\ ${ }^{3}$ Key Laboratory of South China Sea Meteorological Disaster Prevention and Mitigation of \\ Hainan Province, Haikou 570203, Hainan Province, P. R. China \\ *Corresponding author \\ e-mail: huanghai8815@163.com
}

(Received 15 $5^{\text {th }}$ Mar 2019; accepted $1^{\text {st }}$ May 2019)

\begin{abstract}
The yield of rubber tree is influenced by environmental factors and its own variety characteristics. In this study, a simulation model for the stem volume of standing rubber trees was developed. Compared to the general model, the RMSE and $\mathrm{R}^{2}$ values between the simulated and measured data were increased by $28.0 \%$ and $4.5 \%$, respectively. Through analysis, the regression model $Y_{d r l}$ (take the relative stem volume increment and climatic variables as independent variables), $Y_{d r 2}$ (take the climatic variables and disaster index as independent variables), and $Y_{d r 3}$ (take the relative stem volume increment, climatic variables and disaster index as independent variables) were established for the dry rubber yield prediction of a single plant. The result showed that, the RMSE and $\mathrm{R}^{2}$ values of the yield prediction model $Y_{d r 3}$ were $0.0354 \mathrm{~kg}$ and 0.9862 , they increased by $76.8 \%$ and $32.6 \%$ with respect to the model $Y_{d r 2}$ and rose $66.8 \%$ and $17.4 \%$ compared to the yield prediction model $Y_{d r r}$, respectively. In applying the prediction model $Y_{d r 3}$ to the yield prediction in different sub-compartments of a rubber plantations, the mean absolute error was $35.7 \mathrm{~kg} / \mathrm{ha}$. This study's newly established model could provide decision support for dry rubber yield prediction of rubber plantation over large areas.
\end{abstract}

Keywords: climatic element, meteorological disaster, rubber tree, stem volume, yield prediction

\section{Introduction}

The rubber tree (Hevea brasiliensis) is currently the main source of natural rubber. This species is native to the Amazon River Basin in South America, and is commonly found in a climatic environments with high temperature, high humidity, and abundant and evenly distributed rainfall, where it can avoid meteorological disasters hazards, such as typhoon, too-low temperature, and drought (Roberts, 1988; Yu et al., 2014).

China is now an important producer of natural rubber, with a yield is the fourth highest globally. In Hainan Province, the cultivated area is about $5.3 \times 10^{5} \mathrm{hm}^{2}$, and the rubber yield accounts for $53 \%$ of the national production, making it the largest production base of rubber in China (Xu et al., 2017). Rubber production is highly sensitive to various climatic factors. The locality in Hainan is prone to typhoons and chilling damage, which are mostly absent from rubber's native range (Chen et al., 2012; Liu et al., 2015; Roy et al., 2017). Against the background of global climate change, extreme weather events are more likely to occur than ever before. This raises a pressing question: How to quantitatively evaluate the effects of climatic element and disasters hazards on the rubber production. Predicting rubber yield is vital for promoting regional rubber production, so new models are presumably needed. 
The theoretical yield of rubber tree is mainly determined by the species variety used (Lacote et al., 1998), while in its non-native range, annual fluctuations in yield are jointly affected by the market (Xu etal., 2017) and climate factors (Devakumar et al., 1998; Rao et al., 1998; Zomer et al., 2014; Golbon et al., 2015; Nguyen and Dang, 2016), in addition to meteorological disasters (Chen et al., 2012; Liu et al., 2015). The regular growth of rubber tree requires more than $2000 \mathrm{~h}$ of annual sunshine duration, over $1500 \mathrm{~mm}$ of annual precipitation, over $150 \mathrm{~d}$ of rainy days in a year, with an average relative humidity of more than $80 \%$ in the planting region. Additionally, the minimum limit temperature for its growth is $18{ }^{\circ} \mathrm{C}$, while higher temperatures and stronger solar radiation are beneficial to this tree's photosynthesis. But if the temperature is $<10^{\circ} \mathrm{C}$ and $>40{ }^{\circ} \mathrm{C}$, then photosynthesis will cease. The range of $18-28^{\circ} \mathrm{C}$ is the most suitable for rubber production, while that of $18-$ $24{ }^{\circ} \mathrm{C}$ is the most suitable for rubber discharging temperatures (Yu et al., 2014; Yang, 1989; Priyadarshan et al., 2005; Kokmila et al., 2010; Carr, 2012).

In evaluating the relationships between climatic factors and rubber yield, much prior research has looked into various climatic factors to establish the yield prediction equation (Yu et al., 2014; Golbon et al., 2015; Nguyen and Dang, 2016; Zhang et al., 2014, 2017; Kim et al., 2017). For example, Yu et al. (2014) analyzed the relationship between the 5-d average yield of a single rubber tapping tree and the following: average temperature 1 day and 1 month before rubber tapping, day-night temperature difference, and sunshine duration 1 day and 1 month before the rubber tapping. They found that the day-night temperature difference was an important factor influencing the rubber yield, and established their yield prediction equation by using partial least squares regression and classification in a regression tree model. Golbon et al. (2015) considered the average value of rainfall, lowest temperature, highest temperature, and maximum relative humidity 30 days before the rubber tapping as the optimum yield predictors; using them, they established a prediction model of rubber yield by using a linear mixed model. Feng et al. (2016) reported that nine climatic factors influencing the rubber yield were ranked as follows: sunshine $>$ highest temperature $>$ average humidity $>$ average temperature $>$ lowest humidity $>$ evaporation $>$ wind speed $>$ lowest temperature $>$ precipitation; based on this they established a monthly rubber yield prediction model for Xishuangbanna, China. In other work, Nguyen and Dang (2016) analyzed the relationship between the yield and the average temperature, average highest temperature, and average lowest temperature, in the rubber tree varieties GT1 and PB235 in Vietnam for three consecutive years (during 2007 2009). Those rubber yields showed significant negative correlation with all three climatic factors. Earlier Liu et al. (2002) reported that a significant correlation between the diameter at breast height and dry rubber yield of two strains, RRIM600 and PR107. Some have researched the correlations among the laticifer differentiation capability of the rubber tree, the combined efficiency of rubber, and the rubber yield; this was then applied to early rubber yield predictions (Chen, 2014; Yu, 2007).

Until now, research on rubber yield prediction has mainly taken a single climatic factor or a physic-ecological index as the main predictor variable, thereby overlooking the effect of meteorological disasters and varietal characteristics on the predicted yield. In this study, the relative stem volume of rubber tree and a disaster index were introduced as the key predictors, and a new forecasting model for the dry rubber yield of rubber tree was developed, tested, and established. This work thus provides a theoretical basis for the accurate yield estimation in the rubber production over large areas of its cultivation in China. 


\section{Materials and methods}

\section{Study site}

Hainan has a tropical oceanic monsoon climate. In this jurisdiction, the annual average temperature of various regions is $23.1 \sim 27.0^{\circ} \mathrm{C}$, with annual precipitation that is $940.8 \sim 2388.2 \mathrm{~mm}$. The annual average sunshine duration is 1827.6 2810.6 h. During years of 2014-2017, rubber plantations differing in their stand ages were selected, as Figure 1 shows, in Dongchang Farm of Dapo Town, Haikou City (Location: N19³6', E110³7'; Rubber cultivation: 1333.3 ha), Xinzhong Farm of Wanning City (Location: N18 $51^{\prime}$, E110 11 '; Rubber cultivation: 5593.3 ha) and Xiqing Farm of Danzhou City (Location: N19 $32^{\prime}$, E109 $28^{\prime}$; Rubber cultivation: 4573.3 ha). The sampling of the forest stand is the pure rubber plantation that has been tapped manually and the cultivated soil is red soil. The variety studied is RRIM600. The spatial position of the plantation sub-compartments is shown in Figure 1.
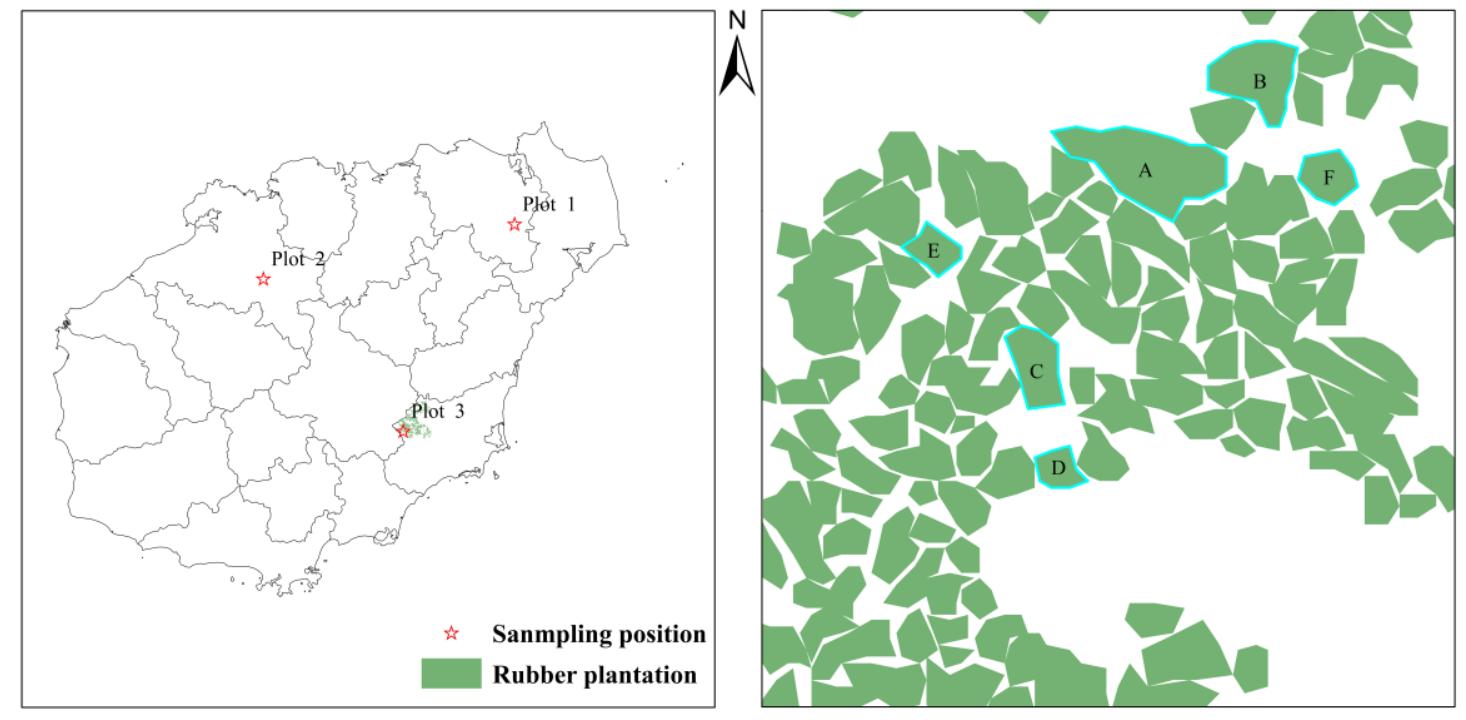

Figure 1. Distribution of sampling points in the study area. (Plot 1 is Dongchang Farm in Haikou City, Plot 2 is Xiqing Farm in Danzhou City, and Plot 3 is Xinzhong Farm in Wanning City. A, B, C,

$D, E$, and $F$ are the sub-compartments of a rubber plantation with different stand ages at the Xinzhong Farm)

\section{Data sources}

\section{Forest characteristics collection}

During 2014-2015, on December 20-31 every year, the sampling was carried out in differently aged stands in plot 1 and 2 . In the sampling rubber plantation of the farm, the tree height, diameter at breast height (at $1.3 \mathrm{~m}$ above the ground) and the thickness of the bark were measured, the crown area was calculated using elliptic area formula (the vertical projection width of the canopy from east to west and north to south was used as diameter). 100 trees were measured at each sampling point every year, a total of 400 samples were obtained until the end of 2015. The data sets applied for training.

During 2016-2017, on December 20-31 every year, the same sampling was carried out in differently aged stands in plot3. 100 trees were measured at this sampling point every year, 
a total of 200 samples were obtained until the end of 2017. The data sets applied for validation.

\section{Data for tree volume calculation}

Differential planimetry is often used to calculate timber volume. In this method, the trunk is divided into several segments, and the volume of each segment is calculated respectively, and finally calculate the volume of the trunk. The precision of this method mainly depends on the number of segments. In this study, the trunk characteristics of rubber trees were comprehensively analyzed, and the number of trunk segments is determined to be 10. The trunk height of the sampled rubber tree was measured, and then the trunk was divided into 10 segments on average according to the height, and the diameter of each segment was measured.

\section{The historical sequence data of tree diameter}

In each plot, 20 rubber trees aged $>40$ years with undamaged tree form were selected for destructive sampling (point 1:45 years old, point 2: 47 years old, point 3: 46 years old). After being felled, a disk of the tree trunk at $1.3 \mathrm{~m}$ was removed and marked in the cardinal directions. The disk was polished until the annual ring boundary was clearly visible. Along the north-south direction of the disk, a section of $1 \mathrm{~cm} \times 30 \mu \mathrm{m}$ was cut by a slicer, and then made into a microsection of annual rings. Under a microscopic projector (XTL-2400), each annual ring width of the section from the pith to the bark was measured to the nearest 0.01 $\mathrm{mm}$. The magnification used was 40x (Rahman et al., 2017). The annual tree wheel width of 20 rubber trees measured at each sampling point was averaged as the annual tree diameter (without bark). The annual tree diameter was multiplied by bark coefficient (bark coefficient $=$ skin diameter/skin diameter) as the historical sequence of tree diameter (with bark).

\section{Meteorological data}

From the Hainan Meteorology Administration, the data of daily mean temperature, precipitation, wind speed and sunshine hours was obtained for the years 1960-2017. From the "tropical cyclone yearbook", the data of maximum wind speed $(\mathrm{m} / \mathrm{s})$ and maximum instantaneous wind speed $(\mathrm{m} / \mathrm{s})$ in each process was obtained for the years 1960-2017.

\section{Rubber production data}

The data on rubber yields came from production records of farms (Dongchang, Xiqing, Xinzhong) during the same period (1960-2017), including the total production of dry rubber and plant cutting, and further calculate the dry rubber yield of single plant (total production of dry rubber/plant cutting).

\section{Meteorological index}

$\mathrm{K}_{\mathrm{I}}$ is the heat-index, $\mathrm{P}_{\mathrm{I}}$ is the precipitation-index, $\mathrm{R}_{\mathrm{I}}$ is the sunshine-index, and $\mathrm{D}_{\mathrm{I}}$ is the disaster-index, with their calculations made as follows (Eqs. 1-6):

$$
K_{I}=0.724 \sum_{i=1}^{n}\left(T_{1}-18\right)+0.276 \sum_{j=1}^{n}\left(T_{2}-10\right)
$$


$T_{1}$ is the daily average temperature during April-November, $T_{2}$ is the daily average temperature from December in the last year to March in the next year $\left({ }^{\circ} \mathrm{C}\right)$, and $n$ is the number of days of regular rubber tree growth. The critical temperature for this regular growth is $18{ }^{\circ} \mathrm{C}$ and $10^{\circ} \mathrm{C}$.

$$
P_{I}=(P-1500) / n
$$

$P$ is the annual precipitation $(\mathrm{mm})$, with $1500 \mathrm{~mm}$ being the minimum annual precipitation required by the rubber tree; $n$ is the number of rainy days.

$$
R_{I}=\left(R_{i}-2000\right) / 2000
$$

The term $R_{i}$ is the annual sunshine duration (h), with the rubber tree requiring $2000 \mathrm{~h}$ of annual sunshine duration for regular growth.

$$
D_{I}=0.724 I_{\text {te }}+0.276 I_{c}
$$

Itc is the typhoon disaster index. $V_{m 1}, V_{m 2}, R_{t}$, and $R_{m}$ are the standardized values of maximum wind speed $(\mathrm{m} / \mathrm{s})$, maximum instantaneous wind speed $(\mathrm{m} / \mathrm{s})$, total precipitation $(\mathrm{mm})$, and daily maximum precipitation $(\mathrm{mm})$, respectively; $I_{c}$ is the chilling damage index, and $X_{1}-X_{6}$ are the standardized values of yearly lowest extreme temperature $\left({ }^{\circ} \mathrm{C}\right)$, maximum temperature drop in degrees $\left({ }^{\circ} \mathrm{C}\right)$, sustained days of chilling damage, radiant accumulated coldness, advective accumulated coldness, and the sustained days of cold weather process with the longest advection. The coefficients in the formula are calculated by the analytic hierarchy process.

$$
\begin{aligned}
& I_{t c}=0.340 * \sum_{i=1}^{n} V_{m l}^{2}+0.280 * \sum_{i=1}^{n} V_{m 2}^{2}+0.136 * \sum_{i=1}^{n} R_{t}+0.244 * \sum_{i=1}^{n} R_{m} \text { (Eq.5) } \\
& I_{c}=0.064 X_{1}+0.143 X_{2}+0.282 X_{3}+0.100 X_{4}+0.207 X_{5}+0.204 X_{6} \text { (Eq.6) }
\end{aligned}
$$

\section{Calculation of stem volume of felled rubber trees}

The stem volume $(V)$ of a sampled rubber tree was calculated using the average basal area quadrature method (Eq. 7; Zeng, 2011).

$$
\mathrm{V}=\frac{\pi}{4}\left(\frac{D_{0}^{2}+D_{10}^{2}}{2}+\sum_{i=1}^{9} D_{i}^{2}\right) \epsilon
$$

In this formula, $V$ is the stem volume of fallen tree $\left(\mathrm{m}^{3}\right) ; D_{0}, D_{n}$, and $D_{i}$ are the crosssectional diameters of the segment at the bottom, top and in the middle of the trunk $(\mathrm{m})$, respectively; $\theta$ is the segment length; and the number of segments is 10 .

\section{Model construction}

\section{Model construction for the crown area and the height of tree}

Referring to previous studies, it can be seen that the relation between tree height and the diameter at breast conforms to Richard equation, and the crown area and the diameter at breast conform to Weibull equation (Zeng et al., 1999; Bi et al., 2012). The 
tree height model $R H(E q .8)$ and crown area model $R A(E q .9)$ was established respectively.

$$
\begin{gathered}
H_{r}=\lambda_{1} *\left(1+\left(\lambda_{2}-1\right) * \exp \left(-\lambda_{3} *\left(D-\lambda_{4}\right)\right)\right)^{\wedge}\left(1 /\left(1-\lambda_{5}\right)\right) \\
A_{r}=\gamma_{1} *\left(1-\exp \left(-\left(\gamma_{2} *\left(D-\gamma_{3}\right)\right)^{\wedge} \gamma_{4}\right.\right.
\end{gathered}
$$

where $\lambda_{1}, \lambda_{2}, \lambda_{3}, \lambda_{4}, \lambda_{5}, \gamma_{1}, \gamma_{2}, \gamma_{3}, \gamma_{4}$ are the model parameter, $H r$ is tree height (m), $A r$ is crown area $\left(\mathrm{m}^{2}\right)$, and $\mathrm{D}$ is diameter at breast height $(\mathrm{cm})$, respectively.

Stem volume of a single standing tree

A general model(V1) based on tree height and DBH is used to calculate the stem volume of standing tree (Eq. 10) (Gonzalez-Benecke et al., 2012, 2013, 2014; Zhou et al., 1995):

$$
\operatorname{LnV} 1=\alpha_{1}+\alpha_{2} \operatorname{Ln}\left(D^{2} H\right)
$$

where $V$ is the living wood growing stock $\left(\mathrm{m}^{3}\right), D$ is $\mathrm{DBH}$ (the diameter at breast height) $(\mathrm{cm}), H$ is the tree height $(\mathrm{m})$, and $\alpha_{1}$ and $\alpha_{2}$ are the model parameters for estimation.

Since the crown area is an important factor influencing the stem volume of standing tree, by incorporating it into model V1, the stem volume model of a standing tree could potentially be improved. Thus, a prediction model V2 that includes three tree characteristics-namely diameter at breast height, tree height, and crown area-was established, which had the following form (Eq. 11):

$$
\operatorname{Ln}(\mathrm{V} 2)=\alpha_{1}+\alpha_{2} \cdot \operatorname{Ln}\left(D^{2} H\right)+\alpha_{3} \cdot \operatorname{Ln}(C A)
$$

where $\alpha_{1}, \alpha_{2}$, and $\alpha_{3}$ are the model parameters, respectively, for the characteristics: $D$, diameter at breast height $(\mathrm{cm}) ; H$, tree height $(\mathrm{m})$; and $C A$, crown area $\left(\mathrm{m}^{2}\right)$.

\section{Model construction for dry rubber yield prediction}

Under a scenario of reasonable growth management, the theoretical rubber yield is mainly affected by its own strain, while the actual yield is also jointly influenced by environmental factors including the climatic variables and disasters hazards (Zhang et al., 2017; Gouvea et al., 2013; Slipi et al., 2006). During the plantation of rubber trees in Hainan, the first 10 years are usually the non-economic production period, whereas the update and elimination are carried out when the stand age is over 35 years. Therefore, a subsection regression prediction equation was established to forecast the rubber yield of single plant in the economic production period. In this research, the yield model $Y_{d r l}$ including the relative stem volume increment and climatic variables, $Y_{d r 2}$ including the climatic variables and disasters hazards, and $Y_{d r 3}$ including the relative stem volume increment, and both climatic and disaster factors, were established and compared and analyzed (Eqs. 12-14): 


$$
\begin{gathered}
Y_{d r 1}=\left\{\begin{array}{ll}
0 & n \leq 10 \\
\beta_{1}+\beta_{2}\left(\frac{V_{n}-V_{n-1}}{V_{n-1}}\right)+\beta_{3} T+\beta_{4} K_{I}+\beta_{5} P+\beta_{6} R_{I} & 10<n \leq 35 \\
0 & 35<n
\end{array} \mid\right. \\
Y_{d r 2}=\left\{\begin{array}{ll}
0 & n \leq 10 \\
\beta_{1}+\beta_{2} T+\beta_{3} K_{I}+\beta_{4} P+\beta_{6} R_{I}+\beta_{6} D_{I} & 10<n \leq 35 \\
0 & 35<n
\end{array} \mid\right. \\
Y_{d r 3}= \begin{cases}0 & n \leq 10 \\
\beta_{1}+\beta_{2}\left(\frac{V_{n}-V_{n-1}}{V_{n-1}}\right)+\beta_{3} T+\beta_{4} K_{I}+\beta_{5} P+\beta_{6} R_{I}+\beta_{7} D_{I} & 10<n \leq 35 \\
0 & 35<n\end{cases}
\end{gathered}
$$

where $\beta_{1}, \beta_{2}, \beta_{3}, \beta_{4}, \beta_{5}, \beta_{6}$, and $\beta_{7}$ are the model parameters, respectively. $\mathrm{n}$ is tree age.

\section{Model testing}

Using a separate validation dataset, the prediction precision ability of tree height, crown area, stem volume, and yield model were tested. Differences among the simulations in their precision were compared and analyzed by comparing precision differences of the yield models differing in their predictors between the conventional stem volume model and our newly proposed model. The simulation precision of all model variants was assessed by calculating the mean absolute error (MAE), the rootmean-square error (RMSE), and the determination coefficient $\left(\mathrm{R}^{2}\right)$ between the observed and simulated (predicted) values (Yu et al., 2014; Zhang et al., 2014).

$$
\begin{aligned}
\text { RMSE } & =\sqrt{\frac{1}{N} \sum_{t=1}^{N}\left(d_{\text {observe }}-d_{\text {predict }}\right)^{2}} \\
\text { MAE } & =\frac{1}{N} \sum_{t=1}^{N}\left|d_{\text {observe }}-d_{\text {predict }}\right|
\end{aligned}
$$

In Equations 15-16: $d_{\text {observe }}$ and $d_{\text {predict }}$ represent the empirically measured value and predicted value from the model simulations, respectively.

In this study, the statistical analysis of the data was done by programming in MATLAB2016, and the model fitting was done via equation parameter fitting in the software Origin v9.0.

\section{Results}

\section{Model fitting}

\section{Model fitting for tree height and crown area}

Using the sampled data of rubber tree from 2014-2015 (Table 1), the relationship of diameter at breast height (D) against tree height and crown was analyzed. Fitted curves were drawn as shown in Figure 2. Evidently these were non-linear correlations. There is an exponential relationship between the tree height as a function of diameter at breast height, as well as the crown and tree height (Bi et al., 2012; Zeng et al., 1999). 
By the model fitting the data in Table 1, the fitting equations of tree height and crown with the diameter at breast height and tree height as variables were established, respectively, with the fitting results of the equation parameters given in Table 2. All parameters in the equations passed the significance threshold of $p<0.001$. Based on the fitting results of the tree height and crown area models, we obtained corresponding $\mathrm{R}^{2}$, RMSE values that were $0.99,0.84 \mathrm{~m}$ and $0.98,0.77 \mathrm{~m}^{2}$, respectively (as shown in Fig. 3).

Table 1. Summary of individual-tree and stand-level characteristics for rubber trees

\begin{tabular}{c|c|c|c|c|c|c|c|c}
\hline & \multicolumn{4}{|c|}{ Model fitting data (2014-2015) } & \multicolumn{4}{c}{ Validation data (2016-2017) } \\
\hline Variable & Mean & SD & Min & Max & Mean & SD & Min & Max \\
A (year) & 32.3 & 9.73 & 14 & 51 & 33 & 10.82 & 10 & 51 \\
D (cm) & 20.97 & 6.99 & 10.50 & 37.28 & 22.3 & 5.9 & 11.74 & 33.08 \\
H (m) & 14.1 & 7.06 & 3.2 & 25.3 & 16.2 & 6.67 & 3.5 & 24.7 \\
CW (m) & 4.5 & 1.23 & 2.2 & 6.1 & 4.9 & 1.09 & 2.2 & 5.8 \\
CA (m $\left.{ }^{2}\right)$ & 14.7 & 7.55 & 3.8 & 23.2 & 15.8 & 6.12 & 3.7 & 20.9 \\
V (m $\left.{ }^{3}\right)$ & 0.35 & 0.35 & 0.01 & 1.32 & 0.38 & 0.30 & 0.02 & 1.02 \\
\hline
\end{tabular}

$\mathrm{A}$ - tree age; D - diameter at the height of $1.3 \mathrm{~m} ; \mathrm{H}$ - tree height; $\mathrm{CW}$ - crown width; $\mathrm{CA}$ - crown area; $\mathrm{V}$ - stem volume of rubber trees
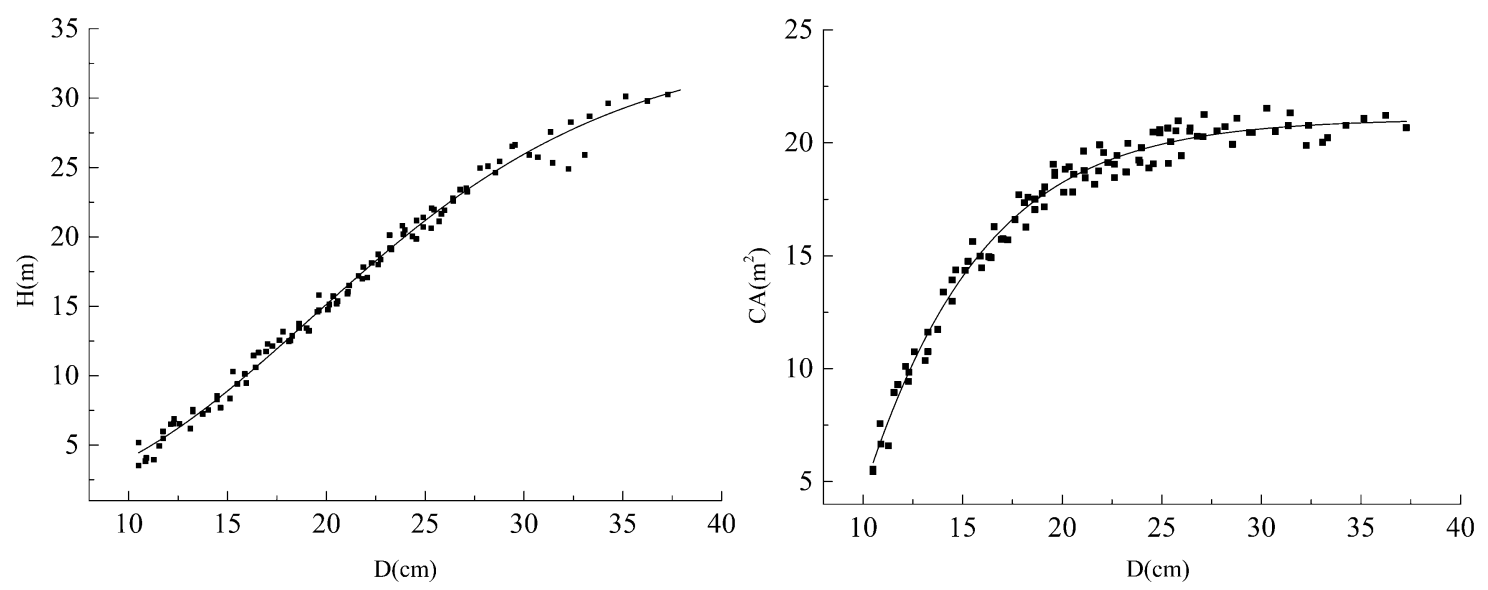

Figure 2. Fitting non-linear relationships between the diameter at breast height $(D)$ against tree height $(H)$ and crown area $(C A)$

\section{Model fitting for stem volume of single standing tree}

The correlations between the stem volume of single standing tree and its diameter at breast height, tree height, and crown area, were all clearly positive. A general model(V1) based on tree height and DBH is used to calculate the stem volume of standing tree (Eq. 10) (Gonzalez-Benecke et al., 2012, 2013, 2014; Zhou et al., 1995). In this research, the existing model has been improved, in that another remarkable factor in the stem volume response was added: crown area. According to Table 1, the binary stem volume model (Eq. 10) and the improved model equation of stem volume (Eq. 11) were established, and the fitting results of their equation parameters are shown in Table 2. These all passed the significance threshold of $p<0.001$. By comparing the 
binary fitting equation of stem volume (V1) to the improved fitting equation (V2), it can be seen that the fitting precision of two equations to the stem volume were both high: When compared with the binary volume model V1, for the improved model V2 added the crown area, RMSE decreases 0.0045 , and reaches $0.0116 \mathrm{~m}^{3}$. Meanwhile, $\mathrm{R}^{2}$ increases 0.0434, and is 0.9975. Hence, the model precision has been improved significantly (as shown in Fig. 3). Therefore, V2 was selected as the volume calculation model.

Table 2. Model parameters and precision statistics

\begin{tabular}{|c|c|c|c|c|c|}
\hline Model & Parameter & Parameter estimate & Standard Error & $\mathbf{R}^{2}$ & RMSE \\
\hline \multirow{5}{*}{$\begin{array}{l}R H \\
(\mathrm{~m})\end{array}$} & $\lambda_{1}$ & 34.6708 & 2.3361 & \multirow{5}{*}{0.9911} & \multirow{5}{*}{0.8424} \\
\hline & $\lambda_{2}$ & 0.1432 & 0.0032 & & \\
\hline & $\lambda_{3}$ & 0.1071 & 0.0018 & & \\
\hline & $\lambda_{4}$ & 18.7575 & 1.2257 & & \\
\hline & $\lambda 5$ & 1.1432 & 0.2316 & & \\
\hline \multirow{4}{*}{$\begin{array}{c}C A \\
\left(\mathrm{~m}^{2}\right)\end{array}$} & $\gamma 1$ & 21.0405 & 2.0134 & \multirow{4}{*}{0.9832} & \multirow{4}{*}{0.7710} \\
\hline & $\gamma 2$ & 8.4217 & 1.1519 & & \\
\hline & $\gamma 3$ & 1.0612 & 0.3513 & & \\
\hline & $\gamma 4$ & 0.1672 & 0.0039 & & \\
\hline \multirow{2}{*}{$\begin{array}{l}\mathrm{V} 1 \\
\left(\mathrm{~m}^{3}\right)\end{array}$} & $\alpha_{1}$ & -10.0614 & 0.2030 & \multirow{2}{*}{0.9541} & \multirow{2}{*}{0.0161} \\
\hline & $\alpha_{2}$ & 1.0352 & 0.0232 & & \\
\hline \multirow{3}{*}{$\begin{array}{l}\mathrm{V} 2 \\
\left(\mathrm{~m}^{3}\right)\end{array}$} & $\alpha_{1}$ & -9.9143 & 2.3016 & \multirow{3}{*}{0.9975} & \multirow{3}{*}{0.0116} \\
\hline & $\alpha_{2}$ & 1.0125 & 0.0131 & & \\
\hline & $\alpha_{3}$ & 0.1739 & 0.0494 & & \\
\hline \multirow{6}{*}{$\begin{array}{c}\text { Ydr1 } \\
\text { (kg/plant) }\end{array}$} & $\beta_{1}$ & -1.6276 & 1.6655 & \multirow{6}{*}{0.7439} & \multirow{6}{*}{0.1525} \\
\hline & $\beta_{2}$ & $19.7356^{* *}$ & 3.2119 & & \\
\hline & $\beta_{3}$ & $0.1319 * *$ & 0.0729 & & \\
\hline & $\beta_{4}$ & $0.0279 * *$ & 0.1699 & & \\
\hline & $\beta_{5}$ & $-0.0112 *$ & 0.0139 & & \\
\hline & $\beta_{6}$ & $0.0588 *$ & 0.0328 & & \\
\hline \multirow{6}{*}{$\begin{array}{c}\text { Ydr2 } \\
\text { (kg/plant) }\end{array}$} & $\beta_{1}$ & $-3.0087 *$ & 1.0936 & \multirow{6}{*}{0.8397} & \multirow{6}{*}{0.1065} \\
\hline & $\beta_{2}$ & $0.2315^{* *}$ & 0.0466 & & \\
\hline & $\beta_{3}$ & $0.0244 * *$ & 0.1181 & & \\
\hline & $\beta_{4}$ & $-0.0110 *$ & 0.0095 & & \\
\hline & $\beta_{5}$ & $0.0571 *$ & 0.0239 & & \\
\hline & $\beta_{6}$ & $-0.3826 * *$ & 0.0363 & & \\
\hline \multirow{7}{*}{$\begin{array}{c}\text { Ydr3 } \\
\text { (kg/plant) }\end{array}$} & $\beta_{1}$ & -0.7201 & 0.4418 & \multirow{7}{*}{0.9862} & \multirow{7}{*}{0.0354} \\
\hline & $\beta_{2}$ & $13.2997 * *$ & 0.8665 & & \\
\hline & $\beta_{3}$ & $0.1150 * *$ & 0.0184 & & \\
\hline & $\beta_{4}$ & $0.0123 * *$ & 0.0417 & & \\
\hline & $\beta_{5}$ & $-0.0092 *$ & 0.0079 & & \\
\hline & $\beta_{6}$ & $0.0571^{*}$ & 0.02152 & & \\
\hline & $\beta_{7}$ & $-0.2975 * *$ & 0.0136 & & \\
\hline
\end{tabular}

*Indicates the factor is significantly correlated with the yield $(\mathrm{p}<0.05)$. **Indicates a significant correlation between the factor and yield $(\mathrm{p}<0.01)$ 

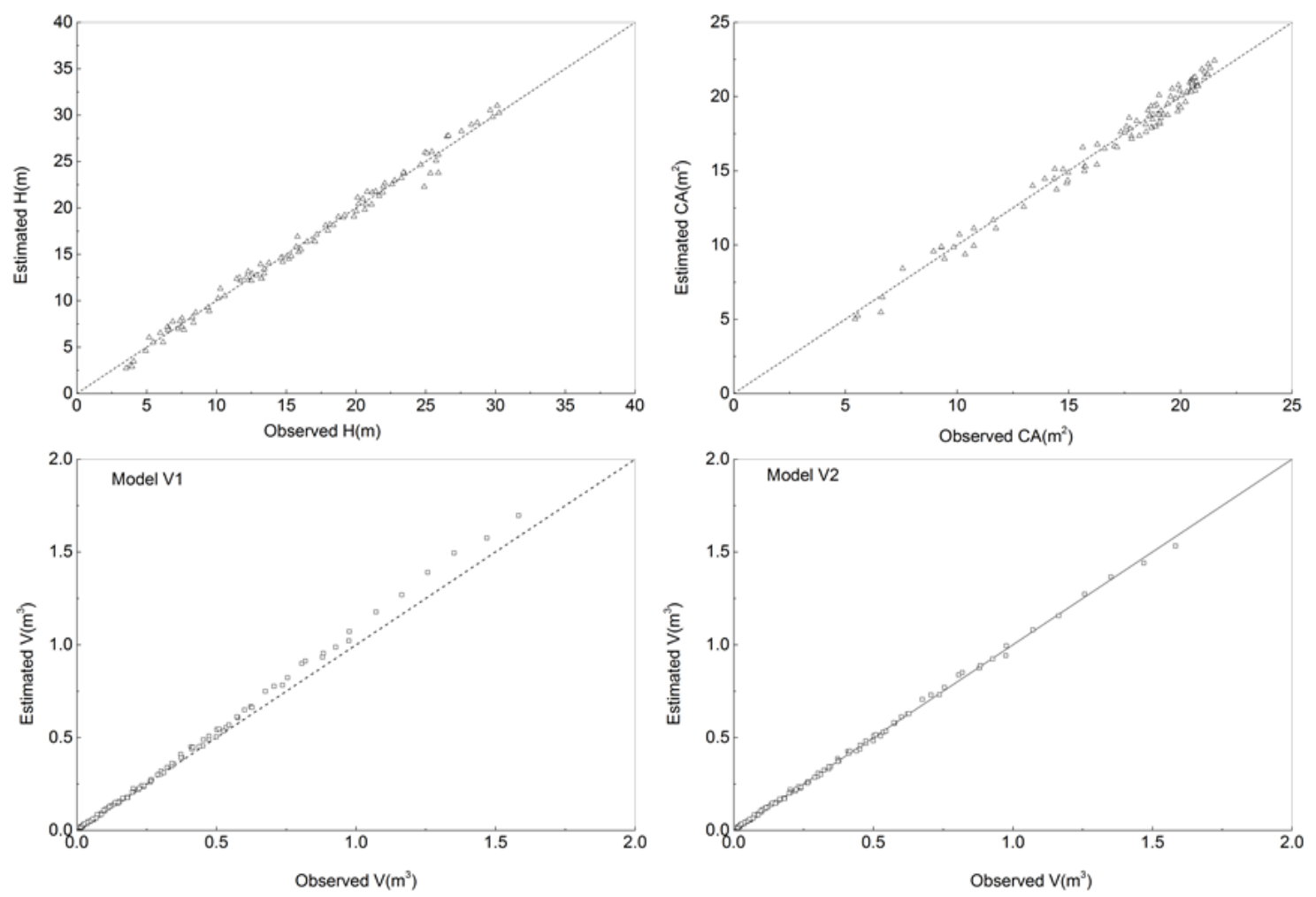

Figure 3. Comparison analysis of the estimated and observed values of tree height $(H)$, crown area $(C A)$, and stem volume $(V)$

\section{Model fitting for yield of a single plant}

By parsing the data of annual ring widths and using the stem volume equation (from the sampling farms of Dongchang and Xiqing), the annual stem volume produced is obtained, and the relative stem volume increment may be calculated. Based on the historical meteorological data of the sampling sites, we calculated the heat, precipitation, sunshine, and disaster indexes. Moreover, the annual average temperature was summarized. From the correlation analysis using the yield of a single plant in the sampling section, it can be seen that the precipitation index $(\mathrm{p}<0.05)$ and disaster index $(\mathrm{p}<0.01)$ are negatively correlated with the yield, while the sunshine index $(\mathrm{p}<0.05)$ and other factors $(\mathrm{p}<0.01)$ are all positively correlated with the yield.

Using the data from Dongchang Farm of Haikou City and Xiqing Farm in Danzhou City, fitting of the models of rubber tree yield $Y_{d r 1}, Y_{d r 2}$, and $Y_{d r 3}$ with the relative stem volume increment, annual average temperature, precipitation index, sunshine index and disaster index as the variables were performed, respectively. Through the follow-up comparison and analysis, the mode $Y_{d r l}$ with relative stem volume increment, annual average temperature, heat index, precipitation index, and sunshine index as the predictor variables showed the lowest precision, having an RMSE and $\mathrm{R}^{2}$ of 0.1525 and 0.7439 , respectively. However, the rubber tree yield models $Y_{d r 2}$ and $Y_{d r 1}$ with annual average temperature, heat index, precipitation index, sunshine index, and disaster index as predictors showed increased RMSE and $\mathrm{R}^{2}$ values, reaching 0.1065 and 0.8397 , respectively. Nevertheless, it was the fitting of the model of rubber tree yield $Y_{d r 3}$ with the relative stem volume increment, annual average temperature, heat index, precipitation index, sunshine index, and disaster index as the predictors, which gave the 
highest precision. Compared with $Y_{d r 1}, Y_{d r 2}$, the corresponding RMSE and $\mathrm{R}^{2}$ values of $Y_{d r 3}$ were $76.8 \%, 32.6 \%$ and $0.9862,0.0354$, respectively (as shown in Fig. 4). Therefore, when trying to forecast the rubber plantation yield, the stem volume increasing as determined by the varietal characteristics is not the only condition affecting the yield. As demonstrated in these results, the climatic variables and disasters hazards are also significant factors that play a role in this prediction of rubber yield. Ydr3 was selected as the yield prediction model in this study.
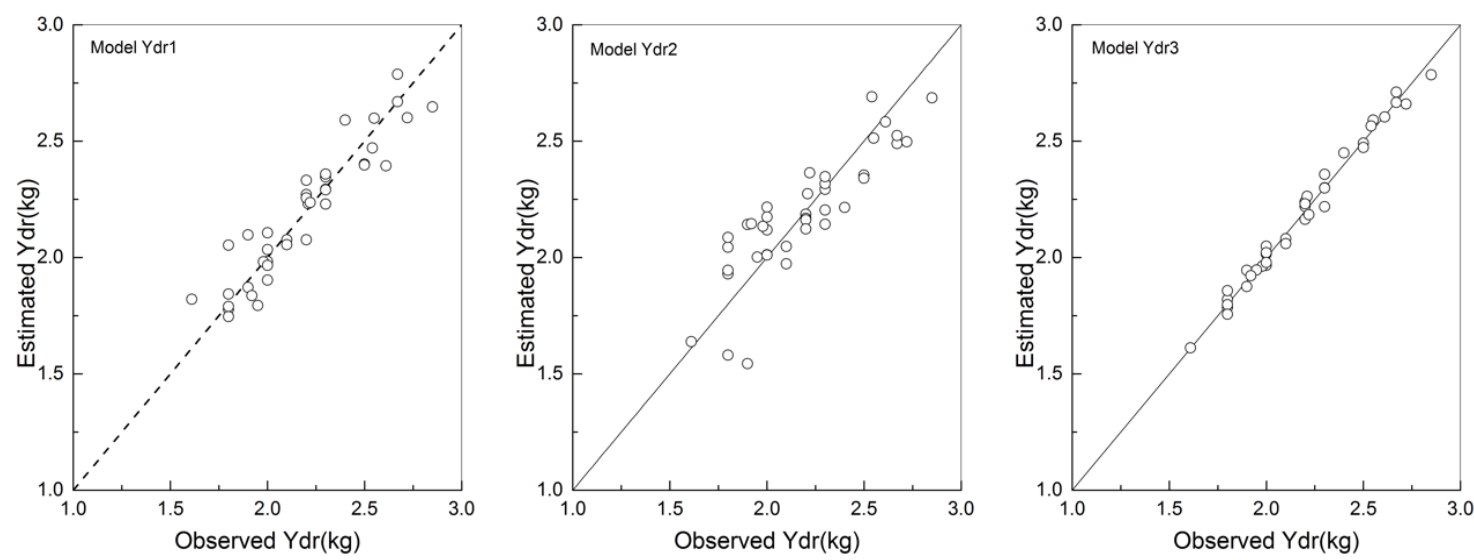

Figure 4. Comparison analysis of the estimated and observed values of dry rubber yield of a single rubber tree

\section{Model validation}

\section{Validation of tree height and crown area}

Based on model $R A$ and $R H$, the sampled data from 2016-2017 (Table 1) in plot3 were used to calculate the tree height and crown area. The model settlement results were compared with the measured data of tree height and crown area for model verification. The results are shown in Table 3 and Figure 5. According to the error analysis of the observed and predicted values, these two models can be used to simulate tree height and canopy area.

Table 3. MAE and RMSE of the observed vs. predicted values verified by the independent data

\begin{tabular}{c|c|c|c|c}
\hline & $\mathbf{H}(\mathbf{m})$ & $\mathbf{C A}\left(\mathbf{m}^{2}\right)$ & $\mathbf{V}\left(\mathbf{m}^{3}\right)$ & Ydr $(\mathbf{k g} / \mathbf{p l a n t})$ \\
\hline MAE & 0.5045 & 0.4750 & 0.0150 & 0.0279 \\
RMSE & 0.5680 & 0.5464 & 0.0157 & 0.0528 \\
\hline
\end{tabular}

\section{Validation of stem volume}

Based on model V2, the sampled data from 2016-2017 (Table 1) in plot3 were used to calculate the stem volume. The model settlement results were compared with the measured data of stem volume for model verification. The results are shown in Table 3 and Figure 5. According to the error analysis of the observed and predicted values, this model can be used to simulate stem volume. 
Validation of dry rubber yield of a single tree

Based on model $Y d r 3$, the sampled data and meteorological statistical data from 2016-2017 (Table 1) in plot3 were used to calculate the dry rubber yield of a single tree. The model settlement results were compared with the measured data of dry rubber yield. The results are shown in Table 3 and Figure 5. According to the error analysis of the observed and predicted values, this model can be used to simulate dry rubber yield of a single tree.
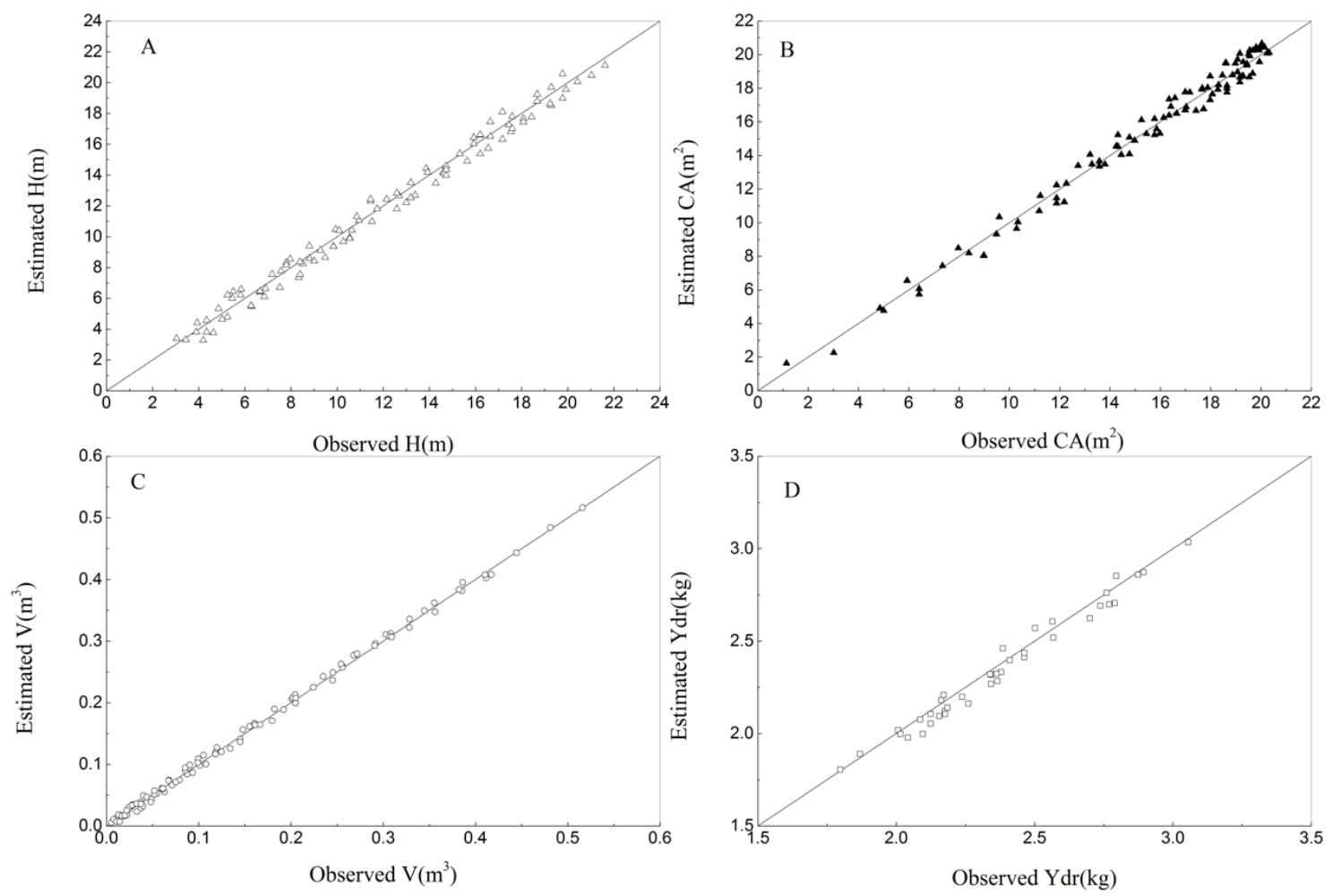

Figure 5. Comparison analysis of the estimated vs. observed values of the rubber tree height $(A)$, crown area $(B)$, stem volume $(C)$, and yield $(D)$

\section{Validation of sub-compartmental dry rubber yield}

The stand-level plantation data (i.e., average diameter, density, and area of woodland) sampled randomly in six different stand sub-compartments (the variety is RRIM600) of Xinzhong Farm (refer to Fig. 1), and the rubber yield data in the subcompartment during 2016-2017 (as shown in Table 4) were used to verify the application of model $Y d r 3$ in actual production. Based on the meteorological observation data, we calculated the heat, precipitation, sunshine, and disaster indexes. Using the established stem volume model V2 and yield model $Y d r 3$, the yield of rubber plantation in 2017 is estimated, and the results are shown in Table 4. This yield simulation shows that the average absolute error of the model in different subcompartments is $35.7 \mathrm{~kg} / \mathrm{ha}$. When the accurate yield estimation is done on a large-scale the precision is high; hence, it can be applied to rubber production on an industrial scale. 
Table 4. Forest stand, yield, and simulated yield of different sub-compartments in 2017

\begin{tabular}{c|c|c|c|c|c|c|c}
\hline \multirow{2}{*}{ Woodland } & \multicolumn{2}{|c|}{$\begin{array}{c}\text { Average diameter } \\
\text { (cm) }\end{array}$} & $\begin{array}{c}\text { Density } \\
\text { (plants/ha) }\end{array}$ & $\begin{array}{c}\text { Area } \\
\text { (ha) }\end{array}$ & $\begin{array}{c}\text { Observed } \\
\text { yield (kg) }\end{array}$ & $\begin{array}{c}\text { Simulate } \\
\text { yield (kg) }\end{array}$ & $\begin{array}{c}\text { MAE } \\
\text { (kg/ha) }\end{array}$ \\
\cline { 2 - 3 } & $\mathbf{2 0 1 6}$ & $\mathbf{2 0 1 7}$ & & & & & \\
\hline A & 18.2 & 19.4 & 423 & 6.8 & 9015.0 & 8922.7 & 34.2 \\
B & 26.3 & 27.2 & 398 & 4.3 & 4706.4 & 4753.6 & 38.9 \\
C & 19.5 & 20.2 & 411 & 3.4 & 3675.2 & 3701.3 & 31.2 \\
D & 17.4 & 18.8 & 458 & 1.3 & 1711.7 & 1696.2 & 35.0 \\
E & 25.2 & 26.2 & 401 & 1.5 & 1870.7 & 1856.1 & 41.0 \\
F & 15.6 & 16.7 & 436 & 1.9 & 2144.9 & 2169.5 & 34.0 \\
\hline
\end{tabular}

The average diameter is the mean value of 30 randomly trees in each sub-compartment, and the yield is the actual yield in the sub-compartment; the simulated yield is the product of the yield of singe plant and the total number of rubber trees which can be tapped

\section{Discussion}

The general stem volume model of rubber trees is mainly based on DBH and tree height (Gonzalez-Benecke et al., 2012, 2013, 2014; Zhou et al., 1995). Previous studies have shown that the crown growth of trees is closely related to stem volume, which generally increases with the decrease of crown length (Liu et al., 2002). Therefore, this study improved the existing model by adding another important response factor of stem volume, canopy area, and significantly improved the model accuracy (see Fig. 3).

In this study, when establishing the prediction model of rubber yield per plant, we consider the actual growth of rubber trees and combine it with the actual production, and finally established the prediction model of yield at different stages. Although the volume of rubber tree will increase in seedling stage, it is not cut during production, so the yield is not considered. From the beginning to the flourishing stage is the main economic production period of rubber trees, and the yield fluctuates under the influence of volume increase, climatic factors and disasters. The economic value of the rubber tree in the aging period, will be greatly reduced, so the yield is not taken into account. Therefore, the establishment of a piecewise prediction model for the yield of rubber trees in the main economic production period is more practical than a single prediction model for the whole growth period, which can improve the prediction accuracy of the model.

Previous studies have found that the diameter of rubber trees, the laticifer differentiation capability and the yield of rubber trees are significantly correlated (Chen, 2014; Liu et al., 2002). In our study, the variation and trends analysis in the cumulative growth and annual growth in the stem volume of rubber tree show that (Fig. 6): the volume of rubber trees increased rapidly from seedling stage to sapling stage (1-10 years), and from primary stage to flourishing stage (11-35 years), and decreased significantly from aging stage (35 years), which was consistent with previous studies (Gonzalez-Benecke et al., 2012, 2013; Gouvea et al., 2013; Ohashi et al., 2001; Xu et al., 2002; Luo et al., 2015). The main explanation for this result is that stem volume increment reflects the increase of nutrients and resource capture by the tree's canopy area and the enhancement of the laticifer differentiation capability in the bark, which thus promotes the synthesis of photosynthate and the generation of latex. In the senescence stage, when the stem volume increment is reduced significantly, the diameter at breast height only increases slowly. This is mainly due to the gradual aging 
of secondary phloem system and a gradual decrease in the laticifer differentiation capability, thus resulting in a yield reduction. Therefore, the yield prediction model with the annual volume increment of rubber tree as a variable has higher precision than the prediction equation with only meteorological elements as a variable.

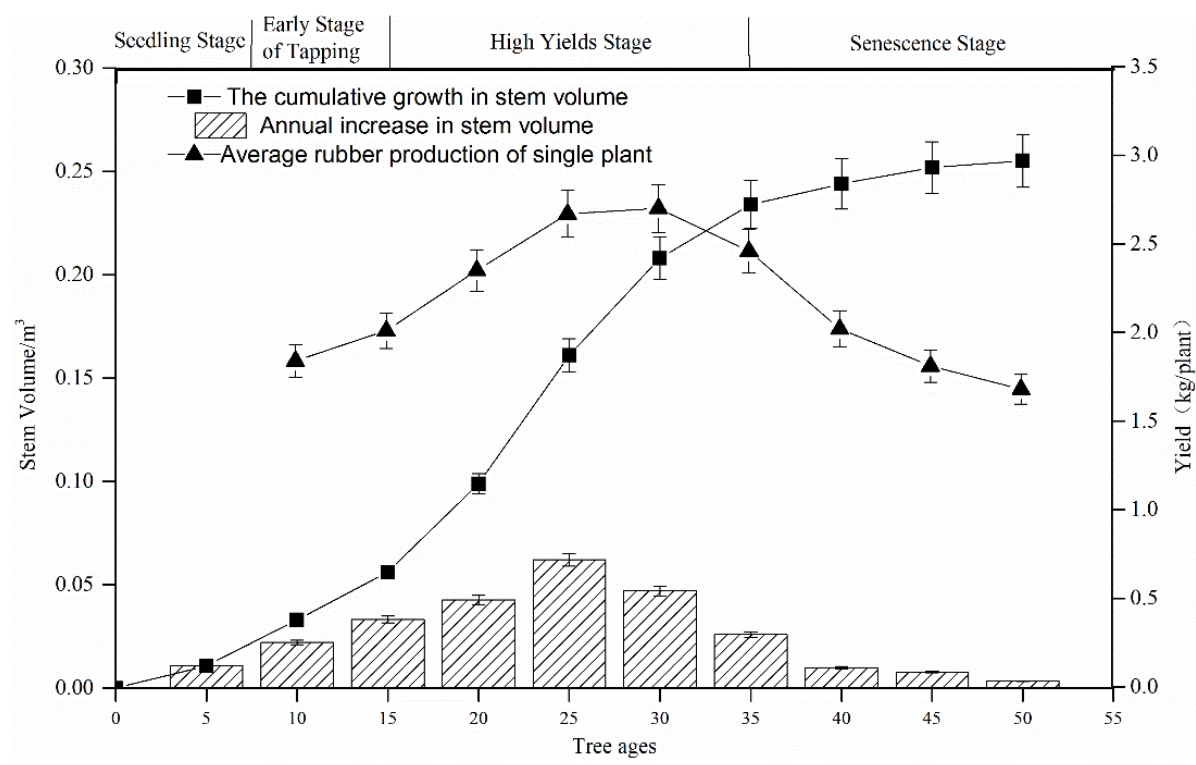

Figure 6. Cumulative growth and annual growth means for the stem volume of rubber tree

Under the condition of standardized and consistent management mode, the annual variation in the trends of the stem volume and yield of rubber tree are mainly determined by tree age and variety, while the differences in the interannual fluctuations is affected by the environmental factors among others, with the climatic variables and meteorological disaster hazard being the main factors influencing the yield of rubber trees. Published research has shown that climate variables, such as the temperature, precipitation, and sunshine, are all closely related to the photosynthesis rate in rubber trees (Roberts, 1988; Devakumar et al., 1998; Satheesan et al., 1984; Rao et al., 1990; Carr, 2012; Zhao et al., 2014), their respiration and transpiration (Zhao et al., 2014), and their synthesis of latex (Lacote et al., 1998; Zomer et al., 2014; Golbon et al., 2015). Therefore, in previous studies, meteorological factors such as temperature, precipitation, humidity and sunshine were often used as variables to establish yield prediction models (Yu et al., 2014; Zhang et al., 2014, 2017; Golbon, 2015; Nguyen and Dang, 2016; Kim et al., 2017). In our study, the heat indexes of effective accumulative temperature over $10{ }^{\circ} \mathrm{C}$ (after the tapping from December to March in the next year) and $18^{\circ} \mathrm{C}$ (from April to November) had significant correlations with the dry rubber yield. The heat index can better reflect the demand for heat in the actual growth of rubber trees than the heat factor that only considers the daily average temperature, average maximum temperature and average minimum temperature (Yu et al., 2014; Nguyen and Dang, 2016). The precipitation index, which included not only the rainy days but also the minimum annual precipitation suitable for the growth of rubber, had a significant negative correlation with the yield. Compared with the previous prediction model of rubber tree yield only considering precipitation, the precipitation index eliminated the effect of cumulative precipitation caused by the increase in rainy days. In a region with 
enough precipitation to meet the regular growth requirement, clearly moisture was not the limiting factor to a change in yield. The rainy days had more obvious effects on the yield (Rao, et al., 1990; Carr, et al., 2012; Zhao, et al., 2014). The disaster index reflected the combined effects of typhoon and chilling damage on the rubber yield. It was significantly positively correlated with the yield, thus suggesting it was also an important factor for the yield prediction. Until now, this important factor was always ignored in prior research publications. In our study, based on the previous prediction model simulating the rubber yield but only considering the climatic variables (average temperature, average maximum temperature, average relative humidity, sunshine duration, and precipitation) (Yu et al., 2014; Zhang et al., 2014, 2017; Golbon, 2015; Nguyen and Dang, 2016; Kim et al., 2017), the collective climate impact was corrected via inclusion of a heat index, precipitation index, and sunshine index. Meanwhile, the relative stem volume increment and disaster index were introduced as predictors to establish a novel model for rubber yield prediction. Compared to the prediction model that uses just a single influencing factor, the precision of our new model was elevated significantly. By applying this yield prediction in the sub-compartment of a rubber plantation, the results revealed that the newly established model was suitable for accurate yield estimation in the study region. As such, it could also provide technical support for the yield forecast or yield loss estimation of different forest sections in the production of rubber over time.

In rubber tree plantations, the stem volume and yield are often impacted by geographical conditions, such as altitude, slope aspect, and slope gradient, albeit to varying extent among sites (Liu et al., 2015; Nguyen, 2013). In our prediction model, these considerations were not further studied, since we sampled a single source. Nonetheless, the stand density did show a certain correlation with the rubber yield: as the stand density increased, the yield of single plant decreased. In our study, the effect of stand density on stand-levels yields was not considered (Naji et al., 2014; Rodrigo and Stirling, 1997). Additionally, the forecasting model for dry rubber in this paper was based on the species variety RRIM600 that was planted in Hainan Province. Hence, the applicability and adaptability of our forecasting to other Chinese regions and cultivated rubber tree varieties requires testing and verification.

\section{Conclusion}

In this study, a simulation model for the stem volume of standing rubber trees on the basis of tree diameter at breast height, tree height and, tree crown area was developed. Based on this result, the relative stem volume increment, annual average temperature, heat index, precipitation index, sunshine index, and disaster index were the main factors considered in a forecasting model for the dry rubber yield of single plant. In applying the prediction model to the yield prediction in the different sub-compartments of a rubber plantation, the mean absolute error was $35.7 \mathrm{~kg} / \mathrm{ha}$. This study's the newly established model could thus provide management with decision support for the dry rubber yield prediction of rubber plantation over large areas.

In the future, the morphological, yield, and meteorological features of rubber tree plantations could be sampled in the main rubber growing regions of China, which would enable a more suitable prediction model to be established. We plan to couple the model with satellite remote sensing technology for rubber plantations of different ages, so that research on the large-scale rubber yield prediction will be advanced. 
Acknowledgements. The study was jointly funded by the NSFC (National Natural Science Foundation of China, Grant no. 41675113; 41765007; 41465005).

\section{REFERENCES}

[1] Bi, H., Fox, J. C., Li, Y., Lei, Y., Pang, Y. (2012): Evaluation of nonlinear equations for predicting diameter from tree height. - Canadian Journal of Forest Research 42: 1-18.

[2] Carr, M. K. V. (2012): The water relations of rubber (Hevea brasiliensis): a review. Experimental Agriculture 48(2): 176-193.

[3] Chen, B. Q., Cao, J. H., Wang, J. K., Wu, Z. X., Tao, Z. L., Chen, J. M., Yang, C., Xie, G. (2012): Estimation of rubber stand age in typhoon and chilling injury afflicted area with Landsat TM data: a case study in Hainan Island, China. - Forest Ecology and Management 274: 222-230.

[4] Chen, Y. Y. (2014): Assessment of the Ability of Secondary Laticifer Differentiation and Efficiency of Rubber Biosynthesis in Relation to Rubber Yield of Rubber Tree. - Hainan University, Haikou.

[5] Devakumar, A. S., Shayee, M. S., Udayakumar, M., Prasad, T. G. (1998): Effect of elevated $\mathrm{CO}_{2}$ concentration on seedling growth rate and photosynthesis in Hevea brasiliensis. - Journal of Biosciences 23(1): 33-36.

[6] Feng, F. F., Zhang, H. Y. (2016): Gray relevancy analysis and the stepwise regression analysis between latex yield and meteorological factors. - Chinese Journal of Tropical Agriculture 36: 57-60.

[7] Golbon, R., Ogutu, J. O., Cotter, M., Sauerborn, J. (2015): Rubber yield prediction by meteorological conditions using mixed models and multi-model inference techniques. International Journal of Biometeorology 59(12): 1747-1759.

[8] Gonzalez-Benecke, C. A., Gezan, S. A., Leduc, D. J., Martin, T. A., Cropper, W. P., Samuelson, L. J. (2012): Modeling survival, yield, volume partitioning and their response to thinning for longleaf pine plantations. - Forests 3(4): 1104-1132.

[9] Gonzalez-Benecke, C. A, Gezan, S. A., Martin, T. A., Cropper, W. P., Samuelson, L. J., Leduc, D. J. (2013): Individual tree diameter, height and volume functions for longleaf pine. - Forest Science 60(1): 43-56.

[10] Gonzalez-Benecke, C. A., Gezan, S. A., Samuelson, L. J., Cropper, W. P., Leduc, D. J., Martin, T. A. (2014): Estimating Pinus palustris tree diameter and stem volume from tree height, crown area and stand-level parameters. - Journal of Forestry Research 25(1): 4352 .

[11] Gouvêa, L. R. L., Silva, G. A. P., Verardi, C. K., Oliveira, A. L. B., de Souza Gonçalves, P. (2013): Simultaneous selection of rubber yield and girth growth in young rubber trees. - Industrial Crops and Products 50: 39-43.

[12] Kim, O. S., Nugent, J. B., Yi, Z. F., Newell, J. P., Curtis, A. J. (2017): A mixed application of geographically weighted regression and unsupervised classification for analyzing latex yield variability in Yunnan, China. - Forests 8(5): 162.

[13] Kokmila, K., Lee, W. K., Yoo, S., Byun, J. G., Lee, S. (2010): Selection of suitable areas for rubber tree (Hevea brasiliensi) plantation using GIS-data in Laos. - Forest Science and Technology 6(2): 55-66.

[14] Lacote, R. C., D’Auzac, A., Gallois, J., Gohet, R., Joet, E., T Pujade Renaud, V. (1998): The biological mechanisms controlling Hevea brasiliensis rubber yield. - Plant 5: 5-17.

[15] Liu, L. H., Chen, D. L., Zhen, H., Wang, Y., H., Yin, G. Y. (2002): The effect of the rate of crown length on the diameter and volume of a tree. - Journal of Agricultural University of Hebei 25(z): 149-150.

[16] Liu, S. B., Lin, W. F. (2002): Correlation studies between tree growth, vessel structural characters and rubber yield in Hevea brasiliensis. - Chinese Journal of Tropical Crops 23(3): 7-11. 
[17] Liu, S. J., Zhang, J. H., Cai, D. X., Zhang, M. J., Tian, G. H., Zou, H. P. (2015): Risk regionalization of rubber plant yield loss in Hainan Island. - Journal of Natural Disasters 24(2): 235-241.

[18] Luo, J. X., Lu, D., Qi, J. Q., Huang, X. Y., Li, F. (2015): Growth ring width and anatomical properties of Toona sinensis wood. - Journal of Southwest Forestry University 35(2): 95-99.

[19] Naji, H. R., Bakar, E. S., Soltani, M., Ebadi, S. E., Abdul-Hamid, H., Javad, S. K. S., Sahri, M. H. (2014): Effect of initial planting density and tree features on growth, wood density, and anatomical properties from a Hevea brasiliensis trial plantation. - Forest Products Journal 64(1): 41-47.

[20] Nguyen, B. T. (2013): Large-scale altitudinal gradient of natural rubber production in Vietnam. - Industrial Crops and Products 41: 31-40.

[21] Nguyen, B. T., Dang, M. K. (2016): Temperature dependence of natural rubber productivity in the southeastern Vietnam. - Industrial Crops and Products 83: 24-30.

[22] Ohashi, Y., Sahri, M. H., Yoshizawa, N., Itoh, T. (2001): Annual rhythm of xylem growth in rubberwood (Hevea brasiliensis) trees grown in Malaysia. - Holzforschung 55(2): 151-154.

[23] Priyadarshan, P. M., Hoa, T. T. T., Huasun, H., De Gonçalves, P. (2005): Yielding potential of rubber (Hevea brasiliensis) in sub-optimal environments. - Journal of Crop Improvement 14(1-2): 221-247.

[24] Rahman, M., Islam, M., Bräuning, A. (2017): Local and regional climatic signals recorded in tree-rings of Chukrasia tabularis in Bangladesh. - Dendrochronologia 45: 111.

[25] Rao, G. G., Rao, P. S., Rajagopal, R., Devakumar, A. S., Vijayakumar, K. R., Sethuraj, M. R. (1990): Influence of soil, plant and meteorological factors on water relations and yield in Hevea brasiliensis. - International Journal of Biometeorology 34(3): 175-180.

[26] Rao, P. S., Saraswathyamma, C. K., Sethuraj, M. R. (1998): Studies on the relationship between yield and meteorological parameters of para rubber tree (Hevea brasiliensis). Agricultural and Forest Meteorology 90(3): 235-245.

[27] Roberts, A. D. (1988): Natural Rubber Science and Technology. - Oxford University Press, New York.

[28] Rodrigo, V. H. L., Stirling, C. M., Teklehaimanot, Z., Nugawela, A. (1997): The effect of planting density on growth and development of component crops in rubber/banana intercropping systems. - Field Crops Research 52(1): 95-108.

[29] Roy, C. B., Newby, Z. J., Mathew, J., Guest, D. I. (2017): A climatic risk analysis of the threat posed by the South American leaf blight (SALB) pathogen Microcyclus ulei to major rubber producing countries. - European Journal of Plant Pathology 148(1): 129138.

[30] Satheesan, K. V., Rao, G. G., Sethuraj, M. R., Raghavendra, A. S. (1984): Canopy Photosynthesis in Rubber (Hevea Brasiliensis): Characteristics of Leaves in Relation to Light Interception. - In: Sybesma, C. (ed.) Advances in Photosynthesis Research. Springer Netherlands, pp. 125-128.

[31] Silpi, U., Thaler, P., Kasemsap, P., Lacointe, A., Chantuma, A., Adam, B., Améglio, T. (2006): Effect of tapping activity on the dynamics of radial growth of Hevea brasiliensis trees. - Tree Physiology 26(12): 1579-1587.

[32] Xu, C. G., Shi, L., Zhong, X. (2017): Analysis of natural rubber market in China in 2016. - Chinese Journal of Tropical Agriculture 36(12): 92-97.

[33] Xu, Y. M., Jiang, Z. H., Ma, W., Yang, R. W. (2002): Variation of growth ring width and wood basic density of rubber tree and their modelling equations. - Scientia Silvae Sinicae 38(1): 95-102.

[34] Yang, S. Q. (1989): The relationship between latex yield and several climatic factors. China. J. Agrometeorol. 10: 42-44. 
[35] Yu, H., Hammond, J., Ling, S., Zhou, S., Mortimer, P. E., Xu, J. (2014): Greater diurnal temperature difference, an overlooked but important climatic driver of rubber yield. Industrial Crops and Products 62(4): 14-21.

[36] Yu, J. H. (2007): Laticifer Differentiation in Adult Rubber Tree and Its Application to Rubber Yield Prediction. - Hainan University, Haikou.

[37] Zeng, Q. S., Luo, Q. B., He, D. B, Xiong, Z. P., Bao, T. H., Zhou, G. H. (1999): Establishment and application of relative tree height models for main tree species in Hainan. - Central South Forest Inventory and Planning 18(2): 1-7.

[38] Zeng, W., S. (2011): The Modeling Method for Single-Tree Biomass. - China Forestry Press, Beijing.

[39] Zhang, H. J., Hua, Y. F., Xu, Z. G., Zhang, L. H., Lan, Z. N., Huang, H. S. (2014): Correlation between latex yield from Hevea brasiliensis and meteorological factors. Chinese Journal of Tropical Agriculture 34(3): 1-3.

[40] Zhang, Y. Y., Wu, Z. X., Wang, X. J., Gao, X. S., Zhang, X. F., Wei, M. M., Huang, X., Li, W. G. (2017): Correlation between meteorological factors and early yield of differentclone rubber trees (Hevea brasiliensis Muell. Arg.) with various rubber production characteristics. - Journal of Southern Agriculture 48(8): 1427-1433.

[41] Zhao, W., Zhang, Y. P., Song, Q. H., Zhang, X., Ji, H. L., Syed, M. N., Yu, L. (2014): Characteristics of transpiration of rubber trees (Hevea brasiliensis) and its relationship with environmental factors. - Chinese Journal of Ecology 33(7): 1803-1810.

[42] Zhou, Z. Z., Zheng, H. S., Yin, G. T., Yang, Z. J., Chen, K. T. (1995): A volume table for Hevea brasiliensis in Leizhou Peninsula. - Forest Research 9(5): 486-491.

[43] Zomer, R. J., Trabucco, A., Wang, M., Lang, R., Chen, H., Metzger, M. J., Xu, J. (2014): Environmental stratification to model climate change impacts on biodiversity and rubber production in Xishuangbanna, Yunnan, China. - Biological Conservation 170: 264-273. 